\title{
Effects of intertrial partial reinforcement and level of acquisition on resistance to extinction
}

\author{
JEFFREY A. SEYBERT, IVAN C. GERARD, JAMES F. MYERS, \\ LISA P. BAER, and ROBERT C. CLIPPER \\ University of Missouri, Kansas City, Missouri 64110
}

\begin{abstract}
In a factorial design, the effects of differential levels of acquisition training on the resistance to extinction generated by intertrial partial reinforcement (ITP) were examined. The results of the experiment indicated that resistance to extinction under conditions of ITP is an increasing function of level of acquisition training. This finding is in contrast to the effects of intertrial reinforcement (ITR) and intertrial nonreinforcement (ITN), which have been shown to attenuate following extended acquisition. The results of the present experiment were explained in terms of a modified discrimination hypothesis.
\end{abstract}

When direct placements in the baited goalbox [known as intertrial reinforcement (ITR)] are interspersed between the nonreinforced $(N)$ and reinforced $(R)$ running trials of a partial reinforcement (PRF) schedule, a reduction in resistance to extinction occurs relative to that produced by PRF alone (e.g., Capaldi, Hart, \& Stanley, 1963). Conversely, nonreinforced goalbox placements [known as intertrial nonreinforcement (ITN)], when interspersed between continuously reinforced (CRF) running trials, result in greater resistance to extinction than that produced by CRF alone (e.g., Brown \& Logan, 1965). If a combination of ITN and ITR placements [known as intertrial partial reinforcement (ITP)] are interspersed between CRF running trials, an increase in resistance to extinction similar to that produced by ITN is observed (e.g., Thieos \& Polson, 1962). It is important to note, however, that ITR and ITN effects are not observed if a large amount of acquisition training is given, i.e., these effects are observed only after limited acquisition (Black \& Spence, 1965; Brown \& Logan, 1965). However, the extent to which differing amounts of acquisition training influence the effects of ITP is not entirely clear. There is some evidence indicating that the effects of ITP, unlike those of ITR and ITN, do not attenuate following extended acquisition (Brown \& Logan, 1965). The purpose of the present experiment was to provide definitive information regarding the importance of different amounts of acquisition training for the effects of ITP.

This research was supported in part by funds from the Graduate Research Council, University of Missouri-Kansas City. Requests for reprints should be sent to J. A. Seybert, Department of Psychology. C. B. Annex, University of Missouri. Kansas City. Missouri 64110.

\section{METHOD}

\section{Subjects}

The subjects were 60 naive male albino Sprague-Dawley rats, purchased from the Holtzman Company at 55 days of age. The subjects were individually housed and randomly assigned to one of six groups $(\mathrm{N}=10 /$ group $)$.

\section{Apparatus}

The apparatus consisted of a $180 \mathrm{~cm}$ long $\times 16 \mathrm{~cm}$ high $\mathrm{x}$ $13 \mathrm{~cm}$ wide straight alley runway constructed of $1 / 2-\mathrm{in}$. pine, painted with alternate vertical black/white stripes $2.22 \mathrm{~cm}$ wide. The runway was divided into a $30-\mathrm{cm}$ start section, a $120-\mathrm{cm}$ run section, and a $30-\mathrm{cm}$ goal section. All sections were covered with hinged hardware-cloth tops and were separated by guillotine doors. The subjects' progress in the alley was measured by three $.01-\mathrm{sec}$ timers. The start timer was activated by the opening of the startbox door and stopped by a photocell $15 \mathrm{~cm}$ into the alley. The run timer was activated by the first photocell and stopped by a second photocell located $15 \mathrm{~cm}$ in front of the goalbox. The goal timer was activated by the second photocell and stopped by a third photocell located $8 \mathrm{~cm}$ inside the goalbox. Start, run, and goal speeds were obtained by converting the start, run, and goal times to reciprocals.

\section{Procedure}

For 5 days after arrival at the laboratory, the subjects were provided food and water ad lib. Following this acclimation period, and 1 week prior to the start of training, they were placed on a deprivation schedule which consisted of a daily ration of $12 \mathrm{~g}$ of Purina Rat Chow, with water available ad lib. The six groups constituted a 3 (Levels of Acquisition by 2 (Reward Schedule) factorial design. The levels of acquisition were 96, 300, and 600 running trials, and the reward schedules were CRF (continuously reinforced running trials) and ITP (continuously reinforced running trials plus three placements in each daily session). The six groups were thus designated CRF-96, CRF-300, CRF-600, ITP-96, ITP-300, and ITP-600, respectively. Four days of pretraining immediately preceded acquisition training for all subjects: The 1 st and 2 nd days consisted of one reinforced running trial in the apparatus, and the 3rd and 4th days consisted of two such trials. Two .75-cm lengths of Startina Hog Starter constituted a reinforcement on both running trials and placements. Nonreinforcement consisted of $15 \mathrm{sec}$ confinement in the unbaited goalbox on both running trials and placements. Both pre- 
training and acquisition were staggered so that acquisition ended for all groups on the same day. Prior to their introduction into the experiment, the subjects in the 300- and 96trial groups were transported to the experimental room, handled, and fed an amount of Startina equal to that received by the 600-trial subjects in their daily schedule of trials and placements. All groups were thus equated for experience outside the home cage, handling, and amount of reinforcement throughout the experiment. Subjects in the CRF groups received six reinforced running trials per day in the runway. Subjects in the ITP groups also received six reinforced running trials per day but, in addition, experienced three goalbox placements per day. The schedule of running trials and placements for the ITP groups were as follows: Day 1-RRnRRrRrR, Day 2RnRRrRRnR, Day 3-RRrRnRRrR, Day 4-RrRnRRRnR $(R=$ reinforced trial, $r=$ reinforced placement, and $n=$ nonreinforced placement). This schedule was repeated, as necessary, for the three ITP groups.

Following acquisition, all subjects received 6 extinction trials per day for 8 days, a total of 48 extinction trials. Extinction trials were conducted exactly the same as nonreinforced running trials during acquisition (for the ITP groups, placements were discontinued during extinction). During both acquisition and extinction, the subjects were run in squads of six, one from each group. The ITI was 5-6 min throughout the experiment.

\section{RESULTS AND DISCUSSION}

Similar results were obtained from all three alley sections, and, thus, only the data from the goal section are reported here.

The data from the last day of acquisition were combined into a single block and analyzed. The main effect for schedule was significant, $F(1,54)=$ $6.64, \mathrm{p}<.05$, indicating that the CRF groups were running faster than the ITP groups at the end of acquisition. The interaction of Level by Schedule was also significant, $F(2,54)=6.09, \mathrm{p}<.01$.

So that the extinction results would not be contaminated by the terminal acquisition-speed differences, the data from the 8 days of extinction (in blocks of six daily trials) were transformed to a rate measure (Anderson, 1963). The subsequent analysis revealed a significant main effect for schedules, $F(1,54)=10.81, p<.01$. As can be seen in Figure 1, this indicates that ITP produced greater resistance to extinction than did $\mathrm{CRF}$ at all three levels of acquisition. A significant main effect of trial blocks was also observed, $F(7,378)=82.30$, $\mathrm{p}<.01$, indicating that response speeds decreased across days of extinction. The significant Schedules by Trial Blocks interaction, $F(7,378)=4.15$, $\mathrm{p}<.05$, was evaluated by post hoc comparisons (Tukey comparisons at the .05 level of significance), which indicated that ITP-96 was more resistant to extinction than was CRF-96 on Days 2, 3, and 4 of extinction; ITP-300 was more resistant to extinction than was CRF-300 on Days 2, 3, 4, and 5; and ITP-600 was more resistant to extinction than was CRF-600 from Day 2 through Day 8. Thus, as is apparent from Figure 1, the present results demon-

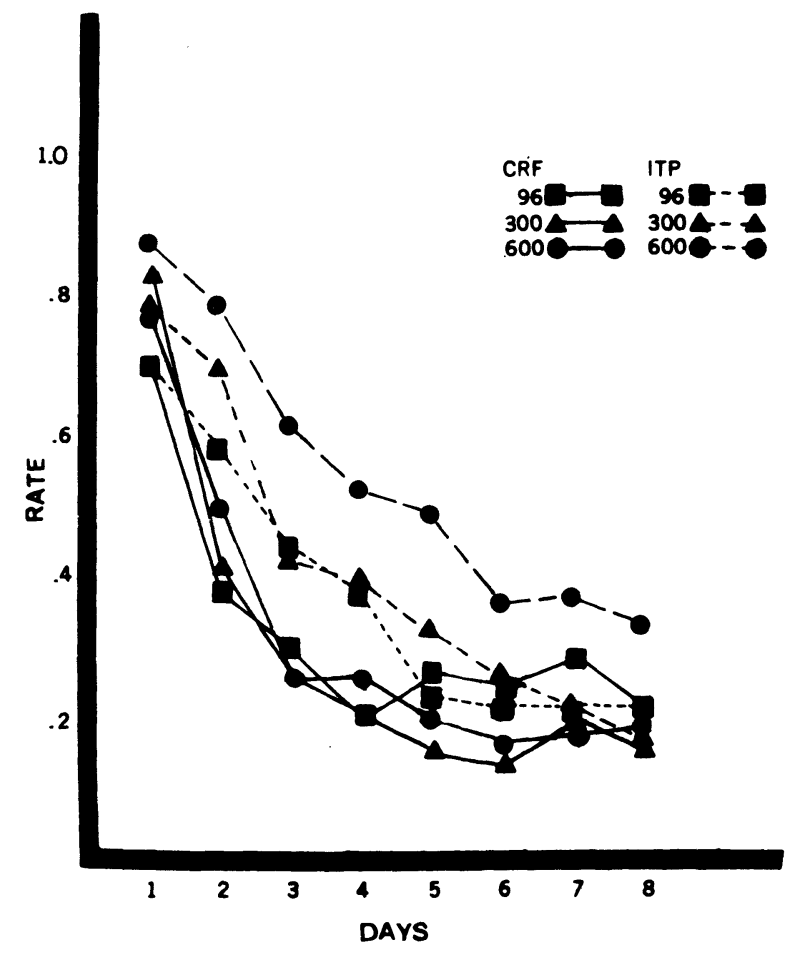

Figure 1. Mean extinction rates in six trial blocks (Days) for all the ITP and CRF groups after 96, 300, or 600 acquisition trials.

strate that differential resistance to extinction is an increasing function of level of acquisition in the ITP paradigm. The differences in resistance to extinction between CRF and ITP, both in terms of magnitude and duration, were least following the fewest acquisition trials and greatest following the largest number of training trials. This finding is opposite that observed in the ITR and ITN paradigms where extended acquisition has been shown to result in an attenuation of the effects of the placements (Black \& Spence, 1965; Brown \& Logan, 1965).

The most often accepted explanation of why increased training results in attenuation of ITR- and ITN-induced changes in resistance to extinction is known as the discrimination hypothesis (Capaldi \& Oliver, 1967). This hypothesis proposes that animals can, if given enough acquisition trials, discriminate between running trials and placements, causing the placements to lose their capacity to produce decreases and increases in resistance to extinction, respectively. The hypothesis has received support from several studies which have shown that rats not only can discriminate running trials from placements, but can use the placements as cues to signal the reward condition on the upcoming running trial (Homzie, Gohmann, \& Hall, 1971; Homzie \& Rudy, 1971). The results of the present experiment have indicated that the effects of ITP do not attenuate after extended training, but rather become stronger as a function of increased numbers 
of training trials. To explain the present results, the discrimination hypothesis would have to at least predict that rats cannot discriminate between running trials and ITP placements, since such a discrimination, according to the hypothesis, is the mechanism which underlies the attenuation of ITN and ITR effects, and no such attenuation occurs for ITP. There is recent evidence, however, that indicates that rats can discriminate running trials from ITP placements (Seybert, Mays, Mellgren, Littlejohn, \& Haddad, Note 1). In two experiments, contrary to the apparent prediction of the discrimination hypothesis, rats were able to discriminate ITP placements from running trials and were able to use the occurrence of placements to signal the presence of either reinforcement or nonreinforcement on the upcoming running trial. Thus, the discrimination hypothesis, in its present form, cannot account for data from ITP procedures. Seybert et al. (Note 1) have proposed a modified version of the discrimination hypothesis which incorporates results of ITP as well as ITR and ITN procedures. Essentially, this explanation holds that the attenuation or maintenance of placement effects is not simply a function of the differentiation of placement and running events. Rather, the attenuation of ITR and ITN effects and the maintenance of ITP effects after extended acquisition training is determined by an interaction of the discrimination of placement and running events with the schedule of $\mathbf{R}$ and $\mathrm{N}$ placements. Both of these factors, i.e., placement schedule and the occurrence of a running-trial/placement discrimination, must be taken into consideration in accounting for placement effects. The present data provide further support for such a hypothesis.

\section{REFERENCE NOTE}

1. Seybert, J. A., Mays, M. Z., Mellgren, R. L., Littlejohn. R. L.. \& Haddaci. N. F. Differential runway performance using goalhox placements and running trials as discriminative stimuli. Manuscript submitied for publication, 1976.

\section{REFERENCES}

Anderson, N. G. Comparison of different populations: Resistance to extinction and transfer. Psychological Revien: 1963. 70, 162-179.

Black. R. W., \& SPENCE, K. W. Effects of intertrial reinforcement on resistance to extinction following extended training. Journal of Experimental Psychology, 1965. 70. 559-563.

Brown, R. T., \& Logan, F. A. Generalized partial reinforcement effect. Journal of Comparative and Physiological Psychology, 1965. 60, 64-69.

Capaldi, E. J.. Hart, D.. \& Stanley, L. R. Effect of intertrial reinforcement on the aftereffect of nonreinforcement and resistance to extinction. Journal of Experimental Psychology, 1963, 65, 70-74.

Capaldi, E. J.. \& Oliver, W. P. Effect of intertrial reinforcement following a substantial number of consistently rewarded trials. Journal of Experimental Psychology, 1967. 75. $135-138$

Homzie. M. J.. Gohmann, R., \& Hall, S. W. Runway performance in rats as determined by the predictive value of intertrial reinforcements. Journal of Comparative and Physiological Psychology. 1971, 74, 90-95.

HomziE. M. J., \& RUDY, J. W. Effect on runway performance of reinforcement contingencies established to empty goal box placements. Learning and Motivation. 1971. 2. $95-101$.

Theios. J. \& Polson, P. Instrumental and goal responses in non-response partial reinforcement. Journal of Comparative and Physiological Psychology, 1962. 55, 987-991.

(Received for publication March 9, 1976.) 